\title{
Response of bacterial communities in rubber plantations to different fertilizer treatments
}

\author{
Zhiyang Zhang ${ }^{1,2} \cdot$ Peisong Zhang ${ }^{2} \cdot$ Qinghuo $\mathrm{Lin}^{2} \cdot$ Zhengzao Cha $^{2} \cdot$ Wei Luo $^{2}$
}

Received: 20 February 2019 / Accepted: 19 June 2019 / Published online: 4 July 2019

(c) The Author(s) 2019

\begin{abstract}
In the present study, the effects of chemical fertilizer (CF) and organic fertilizer plus chemical fertilizer application (OF-CF) on natural rubber yield, soil properties, and soil bacterial community were systematically investigated in rubber plantations. The rubber dry yield was $26.3 \%$ more in the OF treatment group than in the CF treatment group. The contents of total nitrogen (TN), available nitrogen (AN), available phosphorus (AP), and available potassium (AK) as well as soil organic matter (SOM) and $\mathrm{pH}$ value were higher following $\mathrm{OF}-\mathrm{CF}$ treatment. Using Illumina sequencing, a total of 927 operational taxonomic units (OTUs) were obtained following CF treatment, while 955 OTUs were obtained after OF-CF treatment. Relative abundance analysis showed the relative abundances of four phyla (Acidobacteria, Proteobacteria, Actinobacteria, Gemmatimonadetes) were different between the two treatment groups. Correlation analysis revealed Acidobacteria, Bacteroidetes, Thaumarchaeota, Elusimicrobia, Verrucomicrobia were the key taxa that determined the soil properties. Additionally, five OTUs (OTU_506, OTU_391, OTU_189, OTU_278, OTU_1057) were thought to be related to the biodegradation of natural rubber. Taken together, these results improve our understanding of the OF-mediated improvement in soil fertility and contribute to the identification of rubber-degrading bacteria in rubber plantations.
\end{abstract}

Keywords Hevea brasiliensis Muell. Arg. · Natural rubber yield · Organic fertilizer · Chemical fertilizer · Bacterial communities

\section{Introduction}

Chemical fertilizer (CF) significantly increases the yield of crops and has majorly contributed to the green revolution in the twentieth century. However, the mismanagement of inorganic nitrogen and phosphorus inputs is a well-known inefficiency that has posed a threat to the environment (Martínez-Alcántara et al. 2016). Organic fertilizer (OF) has been recently used as substitutes for CF because of they are environmentally friendly. In addition, OF offer an obvious

Electronic supplementary material The online version of this article (https://doi.org/10.1007/s13205-019-1821-6) contains supplementary material, which is available to authorized users.

Wei Luo

rkylw@163.com

1 Institute of Tropical Agriculture and Forestry, Hainan University, Haikou, Hainan, China

2 Rubber Research Institute, Chinese Academy of Tropical Agricultural Sciences, Haikou, Hainan, China advantage of improving carbon sequestration, $\mathrm{pH}$ balance, cation/anion retention, and microbial communities in soil (Zhang et al. 2011). In comparison with CF, OF can regulate soil properties and improve the production of several crops (Liu et al. 2015; Wang et al. 2016a).

Soil microorganisms form complicated microbial communities that regulate the nutrient cycles and influence soil characteristics, plant growth, and ecosystem sustainability (van der Heijden et al. 2008). Bacteria are the most abundant group of soil microorganisms. The determination of soil bacteria is important to understand the bacterial diversity and community composition. Phospholipid fatty acids profiling and 16S rDNA fingerprinting are the key strategies employed for the exploration of soil bacterial communities (Agnelli et al. 2004). With the recent development in second-generation sequencing technologies, high-throughput sequencing has offered great advantages in determining soil microbial diversity and community composition (Kozich et al. 2013; Varma et al. 2018).

The rubber tree is an indigenous species of Amazon rainforests and serves as the sole source of natural rubber for the 
industry. The secondary laticifers located in the inner bark of rubber tree are the site for natural rubber biosynthesis and storage (Hao and $\mathrm{Wu} 2000$ ). Latex, or the cytoplasm of laticifers, contains $20-40 \%$ rubber for natural rubber refinement. During natural rubber production, latex is collected by severing the laticifer rings every $2-3$ days (Chao et al. 2017). The natural rubber yield per tree has significantly grown in the past 100 years, mainly due to variety selection and fertilizer application (Tang et al. 2013). Rubber plantations have become an important ecosystem in tropical areas such as Southeast Asia, Latin America, etc. (Dechner et al. 2018). Although soil bacterial communities of rubber plantations across seasons and chronosequence have been previously reported (Zhou et al. 2017; Lan et al. 2018), their response to different fertilizer treatments is poorly understood. Moreover, the physical properties of natural rubber make the degradation of waste rubber products difficult (Shah et al. 2012). Microbial degradation of natural rubber is an environmentally friendly way, and more than 100 rubber-degrading bacteria have been identified in the past decades (Luo et al. 2014). In the present study, we systematically investigated the effects of $\mathrm{CF}$ and $\mathrm{OF}-\mathrm{CF}$ on natural rubber yield, soil properties, and soil bacterial community composition, and provided some recommendations for the use of OF to improve soil fertility in rubber plantations. Several possible rubber-degrading operational taxonomic units (OTUs) were further discussed.

\section{Materials and methods}

\section{Experimental site and experimental design}

The field experiment was located in the experimental farm of the Chinese Academy of Tropical Agricultural Sciences on Danzhou city, Hainan Province, China (19 $51^{\prime} 51$ N; $\left.109^{\circ} 55^{\prime} 63 \mathrm{E}\right)$. The experiment was conducted in a $4002-\mathrm{m}^{2}$ area ( $3 \mathrm{~m}$ distance between trees and $5 \mathrm{~m}$ between rows, totaling 180 rubber trees). The rubber tree clone "CATAS73397" was planted in 2007 and was tapped in 2015. Beginning in Jan 2017, the experiment was established as a randomized complete block design with two treatment groups as follows: $\mathrm{CF}$ group subjected to $\mathrm{CF}$ treatment; and $\mathrm{OF}-\mathrm{CF}$ group treated with $\mathrm{OF}$ plus $\mathrm{CF}$. Each treatment contained three replicates. For CF treatment, the total CF $(0.322 \mathrm{~kg} \mathrm{~N}$, $0.378 \mathrm{~kg}$ phosphorus pentoxide $\left[\mathrm{P}_{2} \mathrm{O}_{5}\right] 0.24 \mathrm{~kg}$ potassium oxide $\left[\mathrm{K}_{2} \mathrm{O}\right]$ ) per tree was applied in April, July, and September at a proportion of 5:3:2, as per the flowering period of rubber tree (three times each year). For OF-CF treatment, $10 \mathrm{~kg}$ OF $\left(0.187 \mathrm{~kg} \mathrm{~N}, 0.295 \mathrm{~kg} \mathrm{P}_{2} \mathrm{O}_{5}, 0.03 \mathrm{~kg} \mathrm{~K}_{2} \mathrm{O}\right)$ per tree was applied in January as basal fertilizer and the CF $\left(0.135 \mathrm{~kg} \mathrm{~N}, 0.083 \mathrm{~kg} \mathrm{P}_{2} \mathrm{O}_{5}, 0.21 \mathrm{~kg} \mathrm{~K}_{2} \mathrm{O}\right)$ was used as the top dressing in April, July, and September at a proportion of 5:3:2. "The 4th element" $\mathrm{CF}\left(\mathrm{N}+\mathrm{P}_{2} \mathrm{O}_{5}+\mathrm{K} 2 \mathrm{O} \geq 45 \%\right.$, 15-15-15) was produced by Stanley Agriculture Group Co., Ltd. (Shandong, China), while "Wo-Chen biological organic fertilizer" $\mathrm{OF}\left(\mathrm{N}+\mathrm{P}_{2} \mathrm{O}_{5}+\mathrm{K}_{2} \mathrm{O} \geq 5 \%\right.$; organic content $\geq 45 \%$ ) was produced by Woyuan Organic Fertilizers Company (Shandong, China). The main source of OF came from animal manure.

\section{Soil samples collection}

In December 2017, 180 soil cores (50 $\mathrm{cm}$ from the rubber tree trunk at a depth of $20 \mathrm{~cm}$ ) were collected and categorized into six groups (two treatments, three replicates). Each soil sample was passed through a $2-\mathrm{mm}$ mesh sieve before sampling. In each group, soil samples were pooled and split into two collections; one was used for the determination of soil properties, and other was stored at $-80^{\circ} \mathrm{C}$ for soil microbiological high-throughput sequence analysis.

\section{Soil properties determination}

\section{Soil pH}

A total of $10 \mathrm{~g}$ air-dried soil sample was added to $20 \mathrm{~mL}$ double-distilled water $\left(\mathrm{ddH}_{2} \mathrm{O}\right)$, and left still for $30 \mathrm{~min}$. The supernatant was used for $\mathrm{pH}$ determination using a $\mathrm{pH}$ meter (FE28-Bio, Mettler-Toledo Sales International GmbH, Greifensee, Switzerland).

\section{Soil organic carbon (SOC)}

About $0.1 \mathrm{~g}$ air-dried soil sample and $0.1 \mathrm{~g}$ silver sulfate $\left(\mathrm{AgSO}_{4}\right)$ were added into $5 \mathrm{~mL}$ potassium dichromate $\left(\mathrm{K}_{2} \mathrm{Cr}_{2} \mathrm{O}_{7}\right)$-sulphuric acid $\left(\mathrm{H}_{2} \mathrm{SO}_{4}\right)$ solution $(0.4 \mathrm{M})$, and treated at $200{ }^{\circ} \mathrm{C}$ in an oil bath for $5 \mathrm{~min}$. The remaining $\mathrm{K}_{2} \mathrm{Cr}_{2} \mathrm{O}_{7}$ was titrated with iron sulfate $\left(\mathrm{FeSO}_{4}\right)$. The content of SOC was calculated from the amount of $\mathrm{K}_{2} \mathrm{Cr}_{2} \mathrm{O}_{7}$ consumed (Li et al. 2009).

\section{Soil total nitrogen (TN)}

A total of $0.1 \mathrm{~g}$ air-dried soil sample was mixed with an accelerator $\left(10 \mathrm{~g}\right.$ potassium sulfate $\left[\mathrm{K}_{2} \mathrm{SO}_{4}\right], 1 \mathrm{~g}$ copper sulfate $\left[\mathrm{CuSO}_{4}\right], 0.1 \mathrm{~g}$ selenium [Se]), and boiled with $30 \mathrm{~mL}$ $\mathrm{H}_{2} \mathrm{SO}_{4}$ for $5 \mathrm{~h}$. Nitrogen content in the digestion solution was determined by KjelMaster K-375 (BÜCHI Labortechnik AG, Flawil, Switzerland) (Wang et al. 2016b).

\section{Available nitrate (AN)}

In brief, $2 \mathrm{~g}$ air-dried soil sample was boiled with $10 \mathrm{~mL}$ calcium chloride $\left(\mathrm{CaCl}_{2}, 0.01 \mathrm{M}\right)$ for $16 \mathrm{~h}$, and the $\mathrm{AN}$ content was determined using the BRAN + LUEBBE auto-analyzer 
(Bran + Luebbe GmbH, Norderstedt, Germany) (Mussa et al. 2009).

\section{Available potassium (AK)}

About $2.5 \mathrm{~g}$ air-dried soil sample was added into $50 \mathrm{~mL}$ sodium bicarbonate $\left(\mathrm{NaHCO}_{3}, 0.5 \mathrm{M}\right)$ and $20 \mathrm{~mL}$ supernatant was collected by centrifuge (12,000 rpm, $10 \mathrm{~min})$. The supernatant was mixed with $5 \mathrm{~mL}$ molybdenum antimony reagent, and the AK content was determined using a PE Lambda 25 UV spectrophotometer (PerkinElmer, Waltham, USA) (Mengel et al. 1993).

\section{Available phosphorus (AP)}

Briefly, $5 \mathrm{~g}$ air-dried soil sample was mixed with $50 \mathrm{~mL}$ ammonium acetate $\left(\mathrm{NH}_{4} \mathrm{OAc}\right)$, and $20 \mathrm{~mL}$ of the supernatant was collected by centrifugation (12,000 rpm, $10 \mathrm{~min}$ ) and used for AP determination using a Sherwood M410 flame photometer (Sherwood Scientific Ltd, Cambridge, UK) (Blake et al. 2003).

\section{Natural rubber yield characteristics analysis}

The natural rubber content per sample was determined as previously described (Chao et al. 2015). In brief, $0.1 \mathrm{~mL}$ acetic acid was dropped into $1 \mathrm{~g}$ latex to obtain rubber coagula. The coagula were soaked in water for $2 \mathrm{~h}$, dried overnight at $55^{\circ} \mathrm{C}$, and weighed. The natural rubber content was defined as follows:

$\frac{\text { Coagula weight }(\mathrm{g})}{1 \mathrm{~g}} \times 100 \%$.

The latex yield $(\mathrm{mL})$ is termed as the volume of latex collected by one tapping. The dry natural rubber yield (g) was determined as the product of natural rubber content $(\%)$ and latex yield $(\mathrm{mL})$.

\section{Microbiological analysis}

\section{DNA extraction}

A total of $0.5 \mathrm{~g}$ frozen soil of each group was used for the extraction of genomic DNA based on the manufacturer's instructions in the Mo Bio Power Soil ${ }^{\mathrm{TM}}$ kit (Mo Bio, Carlsbad, CA, USA). The concentration and quality of DNA were examined by NanoDrop 2000 (Thermo Scientific Inc., Wilmington, DE, USA), and the integrity of the DNA was checked by $1.2 \%$ agarose gel electrophoresis.

\section{S rRNA sequence}

The bacterial 16S rRNA genes were amplified from soil genomic DNA using barcoded universal prokaryotic primers 515-forward (5'-GTG CCA GCM GCC GCG GTA A-3') and 806-reverse (5'-GGA CTA CVS GGG TAT CTA AT- $3^{\prime}$ ), designed against the $\mathrm{V} 4$ region of the bacterial 16S rRNA gene (Kozich et al. 2013). Polymerase chain reaction (PCR) was performed as follows: $95{ }^{\circ} \mathrm{C}$ for $3 \mathrm{~min}$ followed by 35 cycles of $95{ }^{\circ} \mathrm{C}$ for $45 \mathrm{~s}, 50{ }^{\circ} \mathrm{C}$ for $60 \mathrm{~s}$ and $72{ }^{\circ} \mathrm{C}$ for $90 \mathrm{~s}$, as well as a final extension at $72{ }^{\circ} \mathrm{C}$ for $10 \mathrm{~min}$. Each sample was amplified in triplicate, and equimolar amounts of amplicons were pooled for sequencing using the Illumina MiSeq platform (Allwegene Tech., Beijing, China).

\section{Sequence accession numbers}

The sequence information was deposited at the NCBI Sequence Read Archive (SRA) with the accession number SRP159519.

\section{Bioinformatic analyses of sequence data}

Clean sequence data were obtained by removing the incorrect primer sequences as well as the sequences $<200 \mathrm{bp}$ in length with homopolymers longer than six nucleotides, with quality scores below 20, and with ambiguous base calls. Clean data were clustered into OTUs at 97\% sequence similarity using UCLUST (Edgar 2010). The bacterial taxonomic richness, diversity and evenness analysis were evaluated by MOTHUR, an open-source platform integrating multi-software (Schloss et al. 2009). The formula used for the calculation of Chao1 was defined as (Chao 1984):

Chao $1=$ Sobs $+\frac{n(n 1-1)}{2(n 2+1)}$.

The formulae employed for the calculation of Shannon index is defined as (Shannon 1948):

$H=-\sum_{i=1}^{s}\left(p_{i}\right)\left(\ln p_{i}\right)$

The formulae utilized for the calculation of Simpson index is defined as (Simpson 1949):

$$
D=1-\sum_{i=1}^{s} p_{i}^{2}
$$




\section{Statistical analysis}

The correlation among microbial phyla, soil physicochemical characteristics, and natural rubber yield was analyzed with redundancy analysis carried out using the "vegan" package of R (Nietomoreno et al. 2011). Statistical analysis was performed with SPSS Statistics 17.05 using the analysis of variance (ANOVA) based on independentsample $t$ test. The capital letter or $* *$ represents $p<0.01$, while the lower-case letter or $*$ represents $p<0.05$.

\section{Results and discussion}

\section{The difference in soil physicochemical characteristics and natural rubber yield}

The application of CF or OF-CF notably affected several key soil physicochemical characteristics (Table 1). Soil pH is an important factor determining the biochemical processes in soil (Stevens et al. 1998; Du et al. 2010). The over-application of CF causes soil acidification through the release of acidic organic decomposable compounds (Sial et al. 2019), while OF application relieves soil acidification due to the high levels of base cations $\left(\mathrm{Ca}^{2+}, \mathrm{Mg}^{2+}\right.$, and $\left.\mathrm{K}^{+}\right)$concentrations (Zeng et al. 2017). In comparison with $\mathrm{CF}$ treatment, $\mathrm{OF}-\mathrm{CF}$ treatment increased the soil $\mathrm{pH}$ (Table 1). We propose that the high concentration of base cations released from OF may neutralize the acidic anions, and thus prevent soil acidification in rubber plantations. Moreover, the contents of TN, AN, AP, AK, and SOM increased in the soil treated with $\mathrm{OF}-\mathrm{CF}$ (Table 1), hinting that OF application improves the properties of rubber plantation soil. Additionally, the rubber dry yield rose by $26.3 \%$ following OF-CF treatment (48.5 g/tree.tap) as compared with that observed following CF treatment ( $38.4 \mathrm{~g} /$ tree.tap) (Table 1). Thus, we suggest that the improvements in the properties of rubber plantation soil enhance the nutrient uptake efficiency of the

Table 1 Soil properties of rubber plantations upon different fertilizer treatments

\begin{tabular}{lcc}
\hline & CF & OF-CF \\
\hline $\mathrm{pH}$ & $4.39 \mathrm{Ab}$ & $4.74 \mathrm{Aa}$ \\
$\mathrm{SOM}(\mathrm{g} / \mathrm{kg})$ & $15.01 \mathrm{~B}$ & $20.04 \mathrm{~A}$ \\
$\mathrm{TN}(\mathrm{g} / \mathrm{kg})$ & $1.22 \mathrm{~B}$ & $1.82 \mathrm{~A}$ \\
$\mathrm{AN}(\mathrm{mg} / \mathrm{kg})$ & $106.58 \mathrm{~B}$ & $180.02 \mathrm{~A}$ \\
$\mathrm{AP}(\mathrm{mg} / \mathrm{kg})$ & $25.40 \mathrm{~B}$ & $30.27 \mathrm{~A}$ \\
$\mathrm{AK}(\mathrm{mg} / \mathrm{kg})$ & $73.39 \mathrm{Ab}$ & $108.93 \mathrm{~B}$ \\
$\mathrm{RDY}(\mathrm{g} / \mathrm{tree} . \mathrm{tap})$ & $38.40 \mathrm{~B}$ & $48.50 \mathrm{~A}$ \\
\hline
\end{tabular}

The capital letter represents $p<0.01$ while lower case represents $p<0.05$. The same letter indicated no significant difference among groups rubber tree, thereby resulting in an increase in the yield of natural rubber, consistent with the results of previous studies with other crops (Martínez-Alcántara et al. 2016; Wang et al. 2016a).

\section{Analysis of sequencing data and bacterial taxonomic richness}

Soil microbial organisms affect the function of the soil ecosystem and play an important role in the regulation of plant growth. We used the Illumina platform to sequence the $16 \mathrm{~S}$ rRNA from six soil samples (three repetitions for each treatment). After the exclusion of low-quality tags, more than 50,000 clean tags were generated in each pool. The Shannon-Wiener curve showed that the sequencing data were large enough to reflect the information about the bacterial diversity in the samples (Fig. 1). At 97\% similarity, a total of 1071 OTUs were obtained. From the total OTUs, 927 of these OTUs were identified from CF treatment group; 955 OTUs were detected from in OF-CF treatment group; while 916 OTUs were observed in both two treatment groups. The principal coordinate analysis (PCoA) of UniFrac distance matrices indicated that the differences in the microbiota of the two treatment (CF and $\mathrm{OF}-\mathrm{CF}$ ) groups (Fig. 2), suggesting that fertilizer application influences the community structure of the soil bacteria. Chao1, Shannon, and Simpson are the key indexes of bacterial $\alpha$-diversity. In general, Chao1 represents the richness of bacterial communities (Peng et al. 2017). In Fig. 3a, we show that Chao1 was higher in the $\mathrm{OF}-\mathrm{CF}$ treatment group $(1573 \pm 24)$ than that in the CF treatment group $(1502 \pm 36)$. With the exception of bacterial diversity, Shannon index and Simpson index can also reflect bacterial evenness (Yang et al. 2015). In the present study, Shannon index was higher in the OF-CF treatment group $(7.90 \pm 0.10[\mathrm{CF}]$ vs $8.05 \pm 0.08[\mathrm{OF}-\mathrm{CF}])$ (Fig. 3b), while Simpson index was higher in the CF treatment group $(0.0175 \pm 0.0012[\mathrm{CF}]$ vs $0.0146 \pm 0.0008$ [OF-CF]) (Fig. 3c). Considering that Shannon index is negatively correlated with Simpson index, we thus deduce that OF application improves the richness, diversity, and evenness of bacterial communities possibly through soil $\mathrm{pH}$ renovation and nutrient content improvement (Liu et al. 2015; Wang et al. 2016a).

\section{Bacterial community composition and ecological significance of the selected groups}

We grouped the 1071 OTUs into 23 phyla, 58 classes, 77 orders, 133 families, 134 genus, and 23 species (Table S1). At the phylum level, Acidobacteria (relative abundance 28.6-49.5\%) was identified as the dominant phylum, followed by Proteobacteria (12.2-32.6\%), Chloroflexi (15.3-25.0\%), and Actinobacteria (8.6-16.4\%). 
Fig. 1 Shannon-Wiener curve of six samples

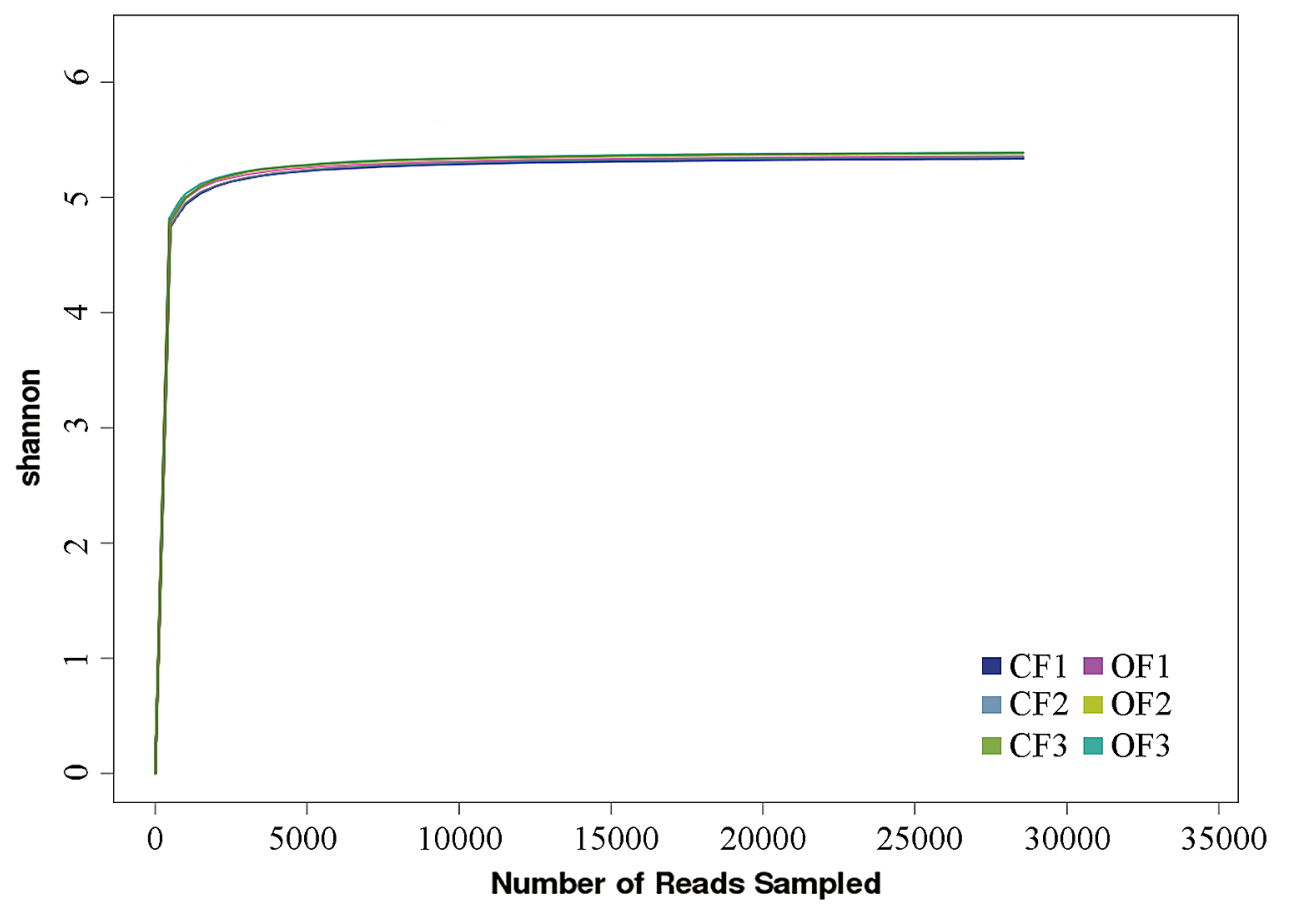

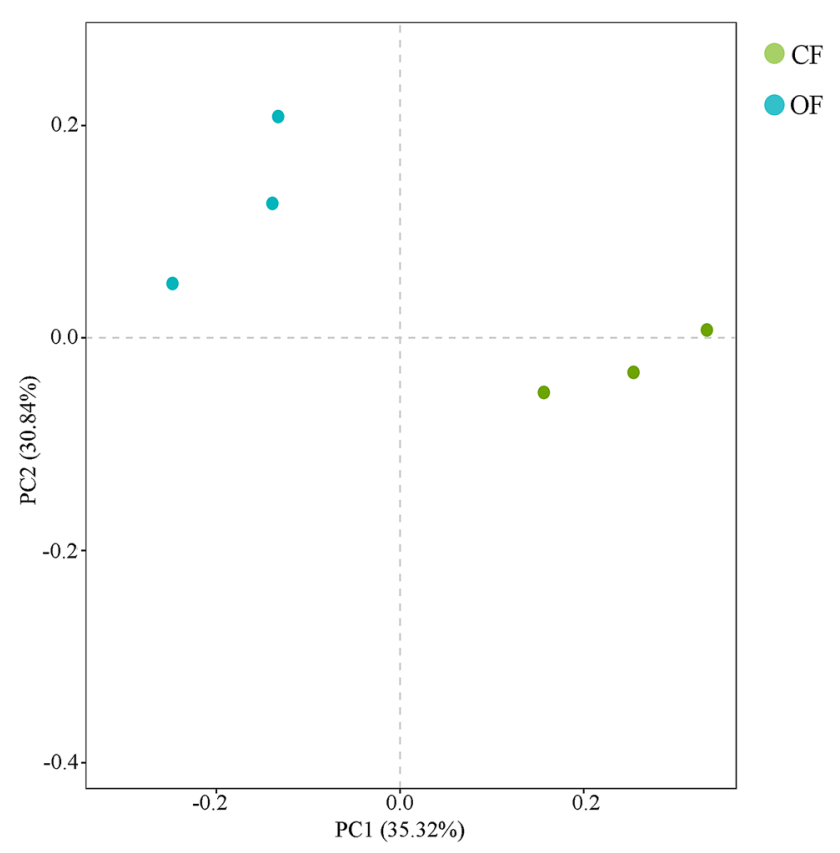

Fig. 2 Principal component analysis of the soil bacterial communities in all six samples

Verrucomicrobia (2.1-3.4\%), Firmicutes (1.7-2.5\%), Planctomycetes (1.3-2.1\%), and Gemmatimonadetes (1.4-1.9\%) were noted as minor phyla. The relative abundance of 11 phyla (Bacteroidetes, GAL15, Latescibacteria, FCPU426, Elusimicrobia, Chlamydiae, Euryarchaeota, Nitrospirae, Cyanobacteria, Saccharibacteria, Parcubacteria, and others) was below $1 \%$ (Fig. 4a). Interestingly, the top five phyla are the same as previously reported (Zhou et al. 2017; Lan et al. 2018), suggesting they are the dominant taxa in rubber plantations. At the species level, several OTUs are termed as "unidentified" (Table S1), indicating that most bacteria in rubber plantations have not been previously identified.

The change in the bacterial communities may reprogram soil properties (Chen et al. 2018). In the present study, we found that the relative abundances of four phyla were different among the two treatment groups (Fig. 4b). Acidobacteria is a group of oligotrophic bacteria found in nutrient-poor and highly acidic soil environments (Jones et al. 2009; Wang et al. 2016a). The abundance of Acidobacteria was higher following CF treatment than after OF treatment $(p=0.0015)$, consistent with the low $\mathrm{pH}$ value of the samples from $\mathrm{CF}$ treatment groups (Fig. 4b; Table 1). Actinobacteria are Gram-positive bacteria, while Proteobacteria and Gemmatimonadetes belong to Gram-negative bacteria. The relative abundances of these phyla were higher in the OF-CF treatment group than that in the CF treatment group $(p=0.0008$, 0.0092, 0.0053 for Actinobacteria, Proteobacteria, Gemmatimonadetes, respectively) (Fig. 4b). Previous researches have shown that some taxa of Actinobacteria, Proteobacteria, and Gemmatimonadetes are beneficial for maintaining or improving soil fertility. Phosphorus (P)-solubilizing bacteria convert insoluble inorganic $\mathrm{P}$ into soluble forms, and play a crucial role in increasing the bioavailability of soil phosphates for plants (Adnan et al. 2017). Bello-Akinosho et al. (2016) identified that a strain belonging to Actinobacteria and two isolates belonging to Proteobacteria phyla displayed 

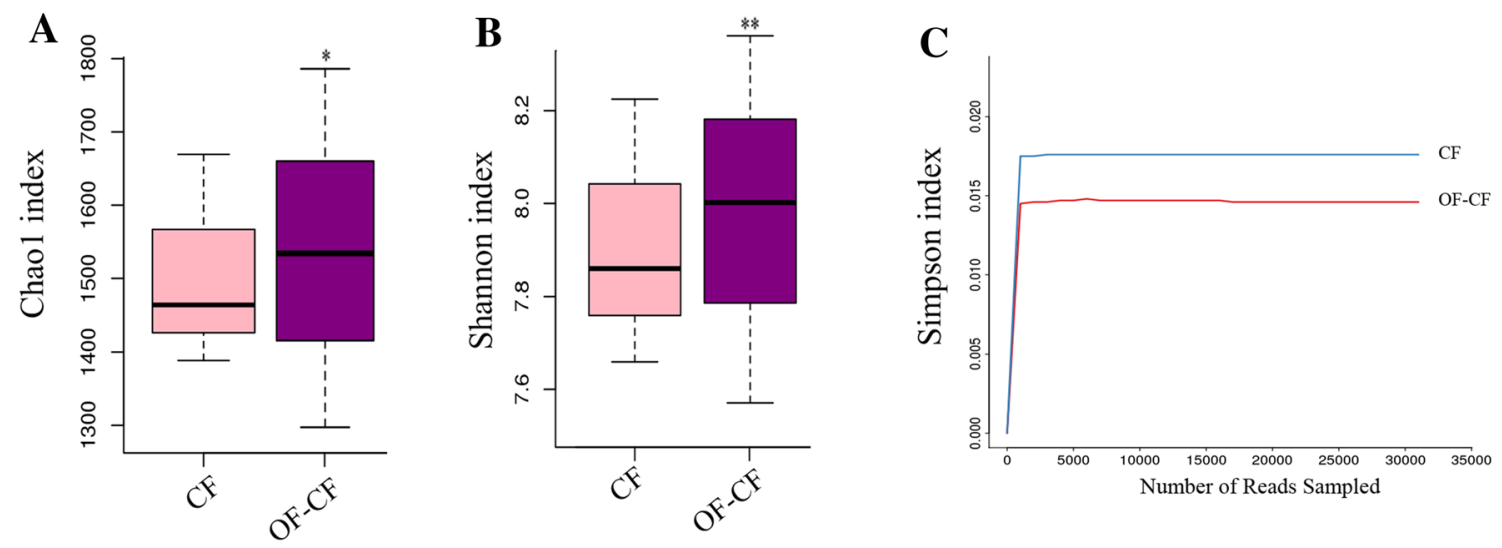

Fig. 3 Chao1 (a), Shannon (b), and Simpson (c) indexes for the different treatments

Fig. 4 Relative abundance of soil bacterial phyla (a) and four phyla (b) under different fertilizers treatments. Average relative abundance was calculated from three replicates. The capital letter represents $p<0.01$ while lower case represents $p<0.05$. The same letter indicated no significant difference among groups
A
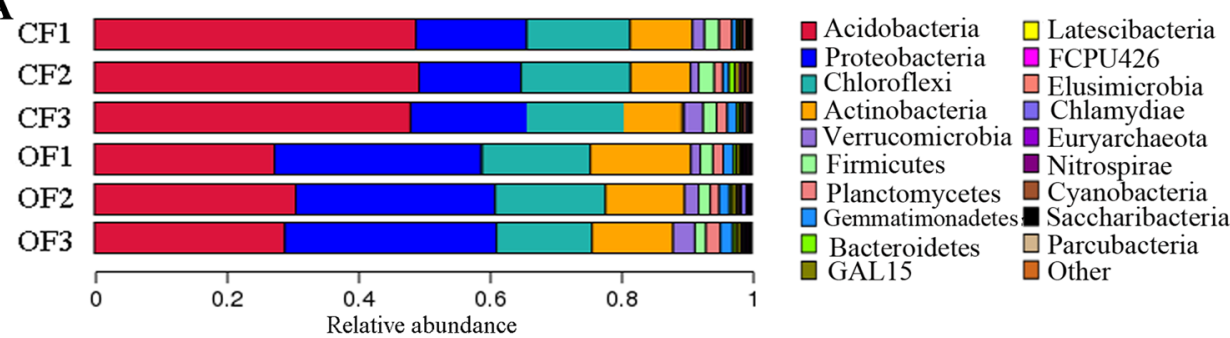

B

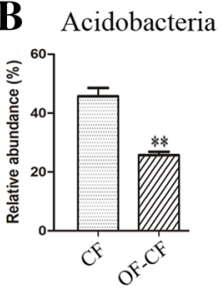

Proteobacteria

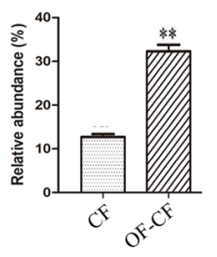

Actinobacteria

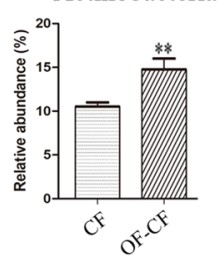

Gemmatimonadetes

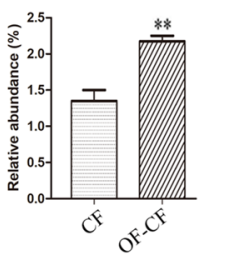

high phosphate solubilization index. Recently, Zeng et al. (2014) reported Gemmatimonadetes as a new phototrophic bacterial phylum, which plays a crucial role in the oxidation of organic compounds and fixation of $\mathrm{N}_{2}$ (Dubbs and Tabita 2004).

\section{Correlation analysis between bacterial taxa and physicochemical characteristics of the selected soil samples}

We performed a correlation analysis between the bacterial taxa and soil physicochemical characteristics. Several phyla showed a strong correlation with soil properties (Fig. 5). Carbon mineralization rate is an important index of carbon availability in soil. By analysis of correlations between soil properties and bacterial taxa abundances, Fierer et al. (2007) reported that the abundances of Bacteroidetes were positively correlated with carbon mineralization rates. In the present study, Bacteroidetes showed a positive correlation with SOM ( $r=0.992)$, an important carbon source for plant. Nitrogen fixation caused by microorganism is a key component of the global nitrogen cycle (Dang et al. 2013). The existence of Ammonia monooxygenase A gene is widespread in ammonia-oxidizing bacteria such as Thaumarchaeota (Dang et al. 2013). Wertz et al. (2012) sequenced the genome of Verrucomicrobia strain Diplosphaera colitermitum, and identified two nitrogen fixation genes: nif and anf. The present results showed Thaumarchaeota and Verrucomicrobia were found to exhibit a positive correlation with TN $(r=0.956)$ and $\mathrm{AN}(r=0.960)$, respectively. As an ancient phylum, Thaumarchaeota possesses $P h n$ gene encoding a phosphonate-specific uptake transporter (Dang et al. 2013). It was observed that Thaumarchaeota showed a positive correlation with AP $(r=0.996)$ in the present study. Evidence suggests that Elusimicrobia phylum plays a key role in nitrogen fixation (Zheng et al. 2016), but in our study, Elusimicrobia showed a positive correlation with AK $(r=0.972)$. 


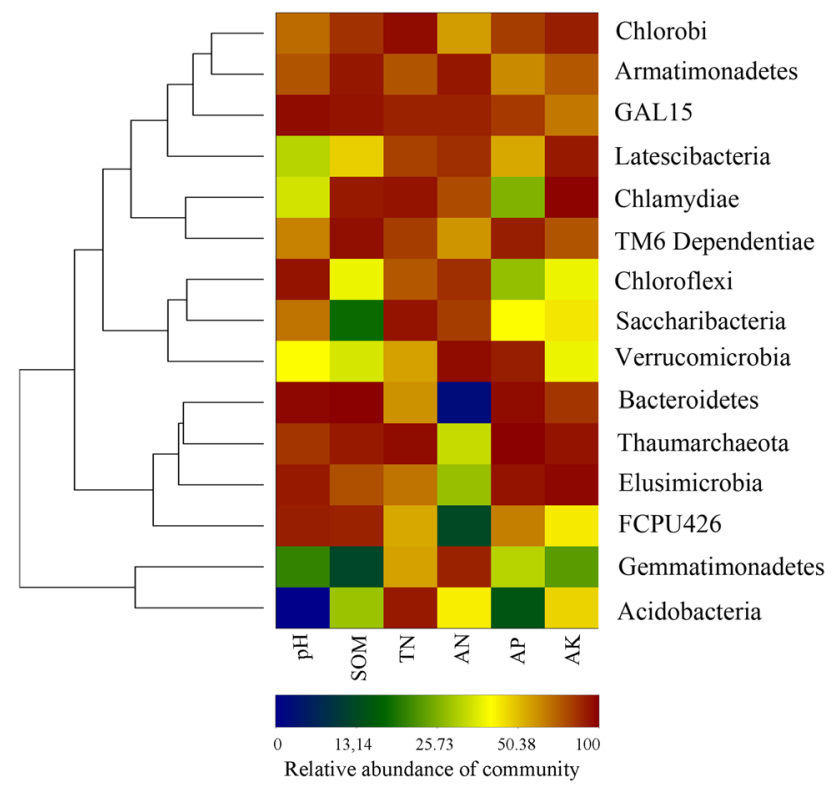

Fig. 5 Correlation heat map between the bacterial phyla and the soil properties. Bar represented the relative abundance of community. Blue color showed negative correlation while red color showed positive correlation

Thus, some taxa within this phylum may regulate potassium transformation in the soil of rubber plantations.

\section{OTUs probably related to natural rubber degradation}

In the past decades, several genera were found to be highly related to natural rubber degradation (Rose and Steinbüchel 2005). Nocardia sp. strain $835 \mathrm{~A}$ is a well-studied rubberdegrading bacterium (Tsuchii et al. 1985). In the present study, we identified that OTU_506 belonged to Nocardia genus (Table S2). The species from Streptomyces genus have been frequently investigated for rubber biodegradation ability. Several Streptomyces spp. may shift rubber molecular mass in response to incubation with natural rubber latex after 10 weeks (Bode et al. 2000; Rose et al. 2004). In this study, we found that OTU_391 belonged to Streptomyces genus (Table S2). The rubber-degrading Mycobacterium fortuitum strain NF4 belongs to Mycobacterium genus. Linos et al. (2000) observed that M. fortuitum NF4 cells were directly embedded and merged into the rubber matrix after 1 week from inoculation. Our sequencing data showed that three OTUs (OTU_189, OTU_278, and OTU_1057) belonged to Mycobacterium genus (Table S2). Future work will involve isolation of these strains and verification of their roles in natural rubber degradation.

\section{Conclusion}

In conclusion, the responses of soil properties and bacterial communities in rubber plantations to $\mathrm{CF}$ or $\mathrm{OF}-\mathrm{CF}$ treatment were systematically investigated. The richness, diversity, and evenness of the bacterial community increased following $\mathrm{OF}-\mathrm{CF}$ application. The relative abundances of several bacterial taxa were reprogrammed, and five bacterial taxa showed a strong correlation with the selected soil properties. Five OTUs were thought to be related to the biodegradation of natural rubber. The results listed here not only provide some recommendations for the understanding of the role of OF in improving soil fertility, but also contribute to the identification of rubber-degrading bacteria in rubber plantations.

Acknowledgements This work was supported by the grant from the National Key R\&D Program of China (No: 2018YFD0201105).

\section{Compliance with ethical standards}

Conflict of interest The authors declare no conflict of interest.

Open Access This article is distributed under the terms of the Creative Commons Attribution 4.0 International License (http://creativeco mmons.org/licenses/by/4.0/), which permits unrestricted use, distribution, and reproduction in any medium, provided you give appropriate credit to the original author(s) and the source, provide a link to the Creative Commons license, and indicate if changes were made.

\section{References}

Adnan M, Shah Z, Fahad S, Arif M, Alam M, Khan IA, Mian IA, Basir A, Ullah H, Arshad M, Rahman IU, Saud S, Ihsan MZ, Jamal Y, Amanullah Hammad HM, Nasim W (2017) Phosphatesolubilizing bacteria nullify the antagonistic effect of soil calcification on bioavailability of phosphorus in alkaline soils. Sci Rep 7(1):16131. https://doi.org/10.1038/s41598-017-16537-5

Agnelli A, Ascher J, Corti G, Ceccherini MT, Nannipieri P, Pietramellara G (2004) Distribution of microbial communities in a forest soil profile investigated by microbial biomass, soil respiration and DGGE of total and extracellular DNA. Soil Biol Biochem 36:859-868. https://doi.org/10.1016/j.soilbio.2004.02.004

Bello-Akinosho M, Makofane R, Adeleke R, Thantsha M, Pillay M, Chirima GJ (2016) Potential of polycyclic aromatic hydrocarbondegrading bacterial isolates to contribute to soil fertility. Biomed Res Int 2016:5798593. https://doi.org/10.1155/2016/5798593

Blake L, Johnston AE, Poulton PR, Goulding KWT (2003) Changes in soil phosphorus fractions following positive and negative phosphorus balances for long periods. Plant Soil 254(2):245-261. https ://doi.org/10.1023/A:1025544817872

Bode HB, Zeeck A, Plückhahn K, Jendrossek D (2000) Physiological and chemical investigations into microbial degradation of synthetic poly(cis-1,4-isoprene). Appl Environ Microbiol 66:3680-3685

Chao A (1984) Non-parametric estimation of the number of classes in a population. Scand J Stat 11:265-270. https://doi. org/10.2307/4615964 
Chao J, Chen Y, Wu S, Tian WM (2015) Comparative transcriptome analysis of latex from rubber tree clone CATAS8-79 and PR107 reveals new cues for the regulation of latex regeneration and duration of latex flow. BMC Plant Biol 15:104. https://doi. org/10.1186/s12870-015-0488-3

Chao J, Yang S, Chen Y, Tian WM (2017) Transcript profiling of Hevea brasiliensis during latex flow. Front Plant Sci 8:1904. https ://doi.org/10.3389/fpls.2017.01904

Chen Y, Liu J, Liu S (2018) Effect of long-term mineral fertilizer application on soil enzyme activities and bacterial community composition. Plant Soil Environ 12:571-577. https://doi.org/10.17221 /658/2018-PSE

Dang H, Zhou H, Yang J, Ge H, Jiao N, Luan X, Zhang C, Klotz MG (2013) Thaumarchaeotal signature gene distribution in sediments of the northern South China Sea: an indicator of the metabolic intersection of the marine carbon, nitrogen, and phosphorus cycles? Appl Environ Microbiol 79(7):2137-2147. https://doi. org/10.1128/AEM.03204-12

Dechner A, Flesher KM, Lindell C, Veiga de Oliveira T, Maurer BA (2018) Determining carnivore habitat use in a rubber/forest landscape in Brazil using multispecies occupancy models. PLoS One 13(4):e0195311. https://doi.org/10.1371/journal.pone.0195311

Du Z, Zhou J, Wang H, Chen X, Wang Q (2010) Soil pH changes from fertilizer site as affected by application of monocalcium phosphate and potassium chloride. Commun Soil Sci Plan 41(15):17791788. https://doi.org/10.1080/00103624.2010.492064

Dubbs JM, Tabita FR (2004) Regulators of nonsulfur purple phototrophic bacteria and the interactive control of $\mathrm{CO}_{2}$ assimilation, nitrogen fixation, hydrogen metabolism and energy generation. FEMS Microbiol Rev 28(3):353-376. https://doi.org/10.1016/j. femsre.2004.01.002

Edgar RC (2010) Search and clustering orders of magnitude faster than BLAST. Bioinformatics 26:2460-2461. https://doi.org/10.1093/ bioinformatics/btq461

Fierer N, Bradford MA, Jackson RB (2007) Toward an ecological classification of soil bacteria. Ecology 88(6):1354-1364. https://doi. org/10.1890/05-1839

Hao BZ, Wu JL (2000) Laticifer differentiation in Hevea brasiliensis: induction by exogenous jasmonic acid and linolenic acid. Ann Bot 85:37-43. https://doi.org/10.1006/anbo.1999.0995

Jones RT, Robeson MS, Lauber CL, Hamady M, Knight R, Fierer N (2009) A comprehensive survey of soil acidobacterial diversity using pyrosequencing and clone library analyses. ISME J 3:442. https://doi.org/10.1038/ismej.2008.127

Kozich JJ, Westcott SL, Baxter NT, Highlander SK, Schloss PD (2013) Development of a dual-index sequencing strategy and curation pipeline for analyzing amplicon sequence data on the MiSeq Illumina sequencing platform. Appl Environ Microbiol 79(17):51125120. https://doi.org/10.1128/AEM.01043-13

Lan G, Li Y, Lesueurd D, Wu Z, Xie G (2018) Seasonal changes impact soil bacterial communities in a rubber plantation on Hainan Island, China. Sci Total Environ 626:826-834. https:// doi.org/10.1016/j.scitotenv.2018.01.147

Li X, Wang Z (2009) Comparison of two soil organic carbon determination methods. Anal Instrum 5:78-80. https://doi.org/10.3969/j. issn.1001-232X.2009.05.019

Linos A, Berekaa MM, Reichelt R, Keller U, Schmitt J, Flemming HC, Kroppenstedt RM, Steinbüchel A (2000) Biodegradation of cis-1,4-polyisoprene rubbers by distinct actinomycetes: microbial strategies and detailed surface analysis. Appl Environ Microbiol 66:1639-1645. https://doi.org/10.1007/s11214-009-9575-9

Liu L, Sun C, Liu S, Chai R, Huang W, Liu X, Tang C, Zhang Y (2015) Bioorganic fertilizer enhances soil suppressive capacity against bacterial wilt of tomato. PLoS One 10(4):e0121304. https://doi. org/10.1371/journal.pone.0121304
Luo Q, Hiessl S, Poehlein A, Daniel R, Steinbüchel A (2014) Insights into the microbial degradation of rubber and gutta-percha by analysis of the complete genome of Nocardia nova SH22a. Appl Environ Microbiol 80(13):3895-3907. https://doi.org/10.1128/ AEM.00473-14

Martínez-Alcántara B, Martínez-Cuenca MR, Bermejo A, Legaz F, Quiñones A (2016) Liquid organic fertilizers for sustainable agriculture: nutrient uptake of organic versus mineral fertilizers in citrus trees. PLoS One 11(10):e0161619. https://doi.org/10.1371/ journal.pone.0161619

Mengel K, Uhlenbecker K (1993) Determination of available interlayer potassium and its uptake by ryegrass. Soil Sci Soc Am J 57(3):761-766. https://doi.org/10.2136/sssaj1993.0361599500 $5700030023 x$

Mussa SAB, Elferjani HS, Haroun FA, Abdelnabi FF (2009) Determination of available nitrate, phosphate and sulfate in soil samples. Int J Pharmtech Res 1(3):598-604

Nietomoreno V, Martínezruiz F, Giralt S, Jiménezespejo F (2011) Tracking climate variability in the western Mediterranean during the Late Holocene: a multiproxy approach. Clim Past 7(4):13951414. https://doi.org/10.5194/cp-7-1395-2011

Peng M, Jia H, Wang Q (2017) The effect of land use on bacterial communities in saline-alkali soil. Curr Microbiol 74:325-333. https:// doi.org/10.1007/s00284-017-1195-0

Rose K, Steinbüchel A (2005) Biodegradation of natural rubber and related compounds: recent insights into a hardly understood catabolic capability of microorganisms. Appl Environ Microbiol 71(6):2803-2812. https://doi.org/10.1128/ AEM.71.6.2803-2812.2005

Rose K, Tenberge KB, Steinbüchel A (2004) Identification and characterization of genes from Streptomyces sp. strain K30 responsible for clear zone formation on natural rubber latex and poly (cis1,4-isoprene) rubber degradation. Biomacromol 6:180-188. https ://doi.org/10.1021/bm0496110

Schloss PD, Westcott SL, Ryabin T, Hall JR, Hartmann M, Hollister EB, Lesniewski RA, Oakley BB, Parks DH, Robinson CJ, Sahl JW, Stres B, Thallinger GG, van Horn DJ, Weber CF (2009) Introducing mothur: open-source, platform-independent, communitysupported software for describing and comparing microbial communities. Appl Environ Microbiol 75:7537-7541. https://doi. org/10.1128/AEM.01541-09

Shah AA, Hasan F, Shah Mutiullah Z, Hameed A (2012) Degradation of polyisoprene rubber by newly isolated Bacillus sp. AF-666 from soil. Prikl Biokhim Mikrobiol 48(1):45-50. https://doi. org/10.1134/s0003683812010140

Shannon CE (1948) A mathematical theory of communication. Bell Syst Tech J 27:379-423. https://doi.org/10.1002/j.1538-7305.1948. tb00917.x

Sial TA, Liu J, Zhao Y, Khan MN, Lan Z, Zhang J, Kumbhar F, Akhtar K, Rajpar I (2019) Co-application of milk tea waste and npk fertilizers to improve sandy soil biochemical properties and wheat growth. Molecules 24(3):423. https://doi.org/10.3390/molecules2 4030423

Simpson EH (1949) Measurement of diversity. Nature 163:688. https ://doi.org/10.1038/163688a0

Stevens RJ, Laughlin RJ, Malone JP (1998) Soil pH affects the processes reducing nitrate to nitrous oxide and di-nitrogen. Soil Biol Biochem 30(8-9):1119-1126. https://doi.org/10.1016/S0038 -0717(97)00227-7

Tang Q, Qin J, Zhao C, Cao Q, Chen J, Liu Z (2013) Economic benefits of rubber plantations in Longjiang farm in Hainan by the application of optimized fertilization formula. Agric Sci Technol 14(12):1788-1791

Tsuchii A, Suzuki T, Takeda K (1985) Microbial degradation of natural rubber vulcanizates. Appl Environ Microbiol 50:965-970 
van der Heijden MG, Bardgett RD, van Straalen NM (2008) The unseen majority: soil microbes as drivers of plant diversity and productivity in terrestrial ecosystems. Ecol Lett 11:296-310. https://doi. org/10.1111/j.14610248.2007.01139.x

Varma VS, Dhamodharan K, Kalamdhad AS (2018) Characterization of bacterial community structure during in-vessel composting of agricultural waste by $16 \mathrm{~S}$ rRNA sequencing. 3 Biotech 8(7):301. https://doi.org/10.1007/s13205-018-1319-7

Wang L, Yang F, Yuan J, Raza W, Huang Q, Shen Q (2016a) Longterm application of bioorganic fertilizers improved soil biochemical properties and microbial communities of an apple orchard soil. Front Microbiol 28(7):1893. https://doi.org/10.3389/fmicb .2016 .01893

Wang H, Pampati N, Mccormick WM, Bhattacharyya L (2016b) Protein nitrogen determination by kjeldahl digestion and ion chromatography. J Pharm Sci 105(6):1851-1857. https://doi. org/10.1016/j.xphs.2016.03.039

Wertz JT, Kim E, Breznak JA, Schmidt TM, Rodrigues JL (2012) Genomic and physiological characterization of the verrucomicrobia isolate Diplosphaera colitermitum gen. nov., sp. nov., reveals microaerophily and nitrogen fixation genes. Appl Environ Microb 78:1544-1555. https://doi.org/10.1128/AEM.06466-11

Yang C, Li Y, Zhou B, Zhou Y, Zheng W, Tian Y, Van Nostrand JD, Wu L, He Z, Zhou J, Zheng T (2015) Illumina sequencing-based analysis of free-living bacterial community dynamics during an Akashiwo sanguinea bloom in Xiamen sea, China. Sci Rep 5:8476. https://doi.org/10.1038/srep08476

Zeng Y, Feng F, Medová H, Dean J, Koblížek M (2014) Functional type 2 photosynthetic reaction centers found in the rare bacterial phylum Gemmatimonadetes. Proc Natl Acad Sci 111(21):77957800. https://doi.org/10.1073/pnas.1400295111

Zeng M, de Vries W, Bonten LT, Zhu Q, Hao T, Liu X, Xu M, Shi X, Zhang F, Shen J (2017) Model-based analysis of the long-term effects of fertilization management on cropland soil acidification. Environ Sci Technol 51(7):3843-3851. https://doi.org/10.1021/ acs.est.6b05491

Zhang N, Wu K, He X, Li S, Zhang Z, Shen B, Yang X, Zhang R, Huang Q (2011) A new bioorganic fertilizer can effectively control banana wilt by strong colonization with Bacillus subtilis N11. Plant Soil 344(1/2):87-97. https://doi.org/10.1007/x1110 4-011-0729-7

Zheng H, Dietrich C, Radek R, Brune A (2016) Endomicrobium proavitum, the first isolate of Endomicrobia class. nov. (phylum Elusimicrobia)-an ultramicrobacterium with an unusual cell cycle that fixes nitrogen with a Group IV nitrogenase. Environ Microbiol 18:191-204. https://doi.org/10.1111/1462-2920.12960

Zhou YJ, Li JH, Ross Friedman C, Wang HF (2017) Variation of soil bacterial communities in a chronosequence of rubber tree (Hevea brasiliensis) plantations. Front Plant Sci 8:849. https:// doi.org/10.3389/fpls.2017.00849 